Received: $\quad 2016.07 .27$ Accepted: 2016.08.22 Published: 2016.10.12

\title{
Comparison of Attitudes of Young Citizens of the Czech Republic, Poland, and Slovakia Towards Liberalization of Legislation Related to Possession of Small Amounts of Marijuana and Other Drugs
}

\section{Authors' Contribution: Study Design A Data Collection B Statistical Analysis C Data Interpretation D Manuscript Preparation E Literature Search F Funds Collection G}

ABCDEF 1,2 Andrzej Brodziak

BCD 3 Pavel Grabczak

BCDF 4 Jana Kutnohorska

BCDG 2 Alicja Różyk-Myrta
1 Institute of Occupational Medicine and Environmental Health, Sosnowiec, Poland 2 Institute of Nursing, University of Applies Sciences, Nysa, Poland

3 Faculty of Healthcare, Alexander Dubček University of Trenčin, Trenčín, Slovakia 4 Department of Health Care Studies, Tomas Bata University, Zlin, Czech Republic
Corresponding Author: Source of support:
Andrzej Brodziak, e-mail: andrzejbrodziak@wp.pl

The work was funded through statutory research performed in 2016 by the University of Applied Sciences in Nysa, Poland

Background: We discuss the countries that have liberalized legislation on the possession of small amounts of marijuana and other drugs, and explore the justifications that inclined authorities to introduce such changes. The Czech Republic is among these countries. We compared the prevailing opinions on this issue by conducting surveys among young people living in Poland, Slovakia, and the Czech Republic.

Material/Methods: The data were collected with the help of Polish, Czech, and Slovak versions of the questionnaire. The data were acquired during 3 focus studies organized at the Department of Health Care, University of Trenčín, Slovakia, the Department of Health Care Studies, Tomas Bata University, Zlin, Czech Republic, and the Institute of Nursing, University of Applies Sciences, Nysa, Poland. We gathered the answers from 27 students of nursing in Zlin, from 43 students in Trenčín, and 33 students in Nysa.

Results: It appears that even in the Czech Republic, many young people disagree with the liberalization of legislation for the possession of small amounts of drugs. The proportion of young Polish students who do not positively assess such legislation is similar. In Slovakia, young people overwhelmingly judge such legislation negatively.

Conclusions: $\quad$ 1. The lack of social approval for the legal possession of small amounts of marijuana makes it difficult to fight dangerous "new psychoactive substances". 2. Since many young people in the Czech Republic, Poland, and Slovakia does not approve of the liberalization of legislation on possessing small amounts of marijuana and other drugs, it is necessary to verify the hypotheses explaining the nature of these prejudices.

MeSH Keywords: $\quad$ Cannabis • Czech Republic • Drug Users • Legislation, Drug • Poland • Slovakia

Full-text PDF: http://medscitechnol.com/abstract/index/idArt/900785

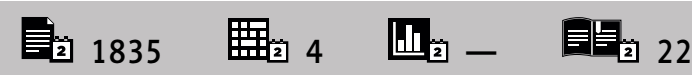




\section{Background}

Some countries have recently introduced legislation decriminalizing the possession of small amounts of drugs, and even allowing legal, although supervised, use of marijuana. In Europe, such changes in legislation have been introduced in the Netherlands, Portugal, Norway, and the Czech Republic.

People working in health care and dealing with securing public health should have a preconceived opinion on these changes and realize the reasons why such changes were implemented. This topic is related to the everlasting phenomenon of reaching for stimulants or substances changing feelings and moods. Many researchers refer to recent papers on the rankings of harmful substances, taking into account alcohol and tobacco [1-4].

These changes in legislation were implemented to diminish the overall cumulative harm caused by the use of drugs. Such legislation facilitates the struggle with the illegal use of the dangerous, so-called new psychoactive substances $[5,6]$. Our former short reports illustrate this struggle $[7,8]$. Attitudes related to drug decriminalization are an important issue in public health. Some researchers tried to investigate these attitudes. Padersen et al. asked 945 students in the UK and Norway to rate the harmfulness of tobacco, alcohol, and cannabis across 5 domains: physical harm, mental health conditions, dependence, injuries, and social consequences [9]. It was found that "tobacco was rated as most harmful to physical harm and dependence; alcohol was rated as most harmful with regard to injuries and social consequences, while cannabis was rated as most harmful to mental health" [9]. The total harmfulness scores for alcohol were higher than those for cannabis. We conclude that their findings may imply that" young people in the years to come may be less supportive of a traditional drug policy based on criminalization, at least when it comes to cannabis. At the same time, one may hypothesize that liberal alcohol policies may receive little support, given students' perception of the possible harm associated with alcohol" [9].

Abolishing the punishment of incarceration for the possession of small amounts of drugs seems to diminishes the personal reactions of retaliation and spread of criminal recruitment. It was discussed recently by several authors.

Having the possibility of conducting surveys among young people living in Poland, the Czech Republic, and Slovakia, we decided to compare the prevailing opinions on this issue.

\section{Material and Methods}

The data were collected with the help of Polish, Czech, and Slovak versions of the questionnaire presented in English in Table 1 . The data were acquired during 3 focus studies, which were organized during one of the authors' presentations (lectures), (A.B.), at the Department of Health Care, University of Trenčin, Slovakia, the Department of Health Care Studies, Tomas Bata University, Zlin, Czech Republic, and the Institute of Nursing, University of Applies Sciences, Nysa, Poland.

The questionnaires in Trenčín, Slovakia were completed by 43 students of nursing (41 women, 2 men), and in Nysa, Poland 33 students ( 31 women and 2 men) completed the survey. The same survey, with a slightly modified question No. 21, was also completed by 27 nursing students ( 25 women and 2 men) in Zlin, Czech Republic. The ages of the people in these groups were very similar and ranged from 19 to 21 years.

We assumed that taking the data from very similar groups of students of nursing, living in Poland, the Czech Republic, and Slovakia, is an appropriate approach for a pilot study related to the assessment of perception of the decriminalization of possession of small amounts of drugs. We relied on the reasoning presented by Sobesky et al. [10], who investigated the attitude of young people in the US state of Colorado. Assessment of the opinions and psychology of young persons is highly predictive of future trends.

The applied questionnaire contained 20 questions enabling us to make a rough estimate of the so-called social capital (i.e., the ability to cooperate). The estimation of the ability of a person to cooperate with others can be expressed by the sum of the answers to questions 1-20. The average ability of a group of individuals to work together can be expressed by the arithmetic mean of the points obtained by the members of this group.

The questionnaire contains an additional question No. 21, related to opinions about the legislation on the legality of possessing small amounts of drugs in the Czech Republic.

Question No. 21 was presented to the examined students of nursing in the context of 20 other questions related to the issue of the ability to cooperate in several different situations.

Due to methodological reasons, the question about the perception of decriminalization of possession of small quantities of drugs should be included in a broader survey on a similar range of social feelings. We chose the issue of ability to cooperate because it is connected with the need of young people for freedom of personal interactions and behaviors. We decided to use our own questionnaire because it has advantages over established tools of assessment of bridging and bonding social 
Table 1. An questionnaire for the assessment of abilities to cooperation and additionally opinion about the legislative regulations related to drugs Female [ ], man [ ]. Age in years..., Current occupation: student [ ] work [ ] Education: gymnasium [ ], lyceum level [ ], bachelor [ ], after second degree [ ].

\begin{tabular}{|c|c|c|}
\hline No & Content of questions: & $\begin{array}{l}\text { In the middle or } \\
\text { I don't know }\end{array}$ \\
\hline 1 & Being in new company do you carefully listen what each speaker wants to say? & \\
\hline 2 & $\begin{array}{l}\text { Being in new company do you like to express your opinion on the topic that is being } \\
\text { discussed? }\end{array}$ & \\
\hline 3 & $\begin{array}{l}\text { Hearing about the new idea of a joint venture, noting the possible benefits and having } \\
\text { free time, are you ready to cooperate? }\end{array}$ & \\
\hline 4 & $\begin{array}{l}\text { Can you continue the cooperation, even though your partners or contributors } \\
\text { comprehend the essence of the problem a little differently than you do? }\end{array}$ & \\
\hline 5 & I highly estimate my own self-value. I feel as an independent person. & \\
\hline 6 & I am almost always in a good mood & \\
\hline 7 & I am not envious & \\
\hline 8 & I perceive life almost every day as exciting & \\
\hline 9 & I am open minded and willing to consider new ideas or proposals & \\
\hline 10 & I evaluate problems realistically & \\
\hline 11 & I am flexible, I avoid conflicts, generally I strive for agreement & \\
\hline 12 & $\begin{array}{l}\text { I have no inclination to control the behavior of others. I avoid judging and criticizing } \\
\text { others }\end{array}$ & \\
\hline 13 & $\begin{array}{l}\text { I have already participated in the past in social activities or projects that require } \\
\text { cooperation }\end{array}$ & \\
\hline 14 & In general, I trust the people. I am convinced that I can count on some people & \\
\hline 15 & $\begin{array}{l}\text { I am able to calmly think through a situation to seek a solution. I usually find a way out } \\
\text { of a difficult situation }\end{array}$ & \\
\hline 16 & I create around me the feeling of security and freedom & \\
\hline 17 & I try to be friendly to others & \\
\hline 18 & $\begin{array}{l}\text { In general I have the feeling that I understand what is happening around me and what } \\
\text { is happening in the world }\end{array}$ & \\
\hline 19 & $\begin{array}{l}\text { I think that I was effective in past collective endeavours and that the cooperation } \\
\text { suited me }\end{array}$ & \\
\hline 20 & I am interested in world events and explanations of ongoing developments & \\
\hline 21 & $\begin{array}{l}\text { Additional research question: Do you think that the legislative regulations in the } \\
\text { neighboring Czech Republic which allow the legitimate possession of small quantities of } \\
\text { drugs (including marijuana) is appropriate and worthy to follow? }\end{array}$ & \\
\hline
\end{tabular}

capital among young people [11-13]. We discussed these advantages in our former paper [14]. In brief, our questionnaire also included some elements of related social values like spiritual, intellectual, experiential, and cultural capital (http://www. appleseedpermaculture.com/about/regenerative-enterprise).

The differences between the average of sums of points for the "ability to cooperate" were assessed using the $t$ test and the Wilcoxon test. The statistical significance of the difference in the proportions of responses to supplementary question No. 21 was verified through the use of the chi-square test. We used the software available at: http://statpages.org/.

\section{Results}

Results related to the frequency of choosing the possible options for answering question No. 21 are presented in Table 2. 
Table 2. Number of answers for three possible options for the question no 21 obtained using the presented questionnaire.

\begin{tabular}{|lcccc|}
\hline & Yes & $\begin{array}{c}\text { In the middle or } \\
\text { I don't know }\end{array}$ & No & $\begin{array}{c}\text { In the middle or } \\
\text { I don't know and No }\end{array}$ \\
\hline Students in Zlin (27) & 11 & 11 & 5 & 16 \\
\hline Students in Trencin (43) & 5 & 13 & 25 & 38 \\
\hline Students in Nysa (33) & 14 & 9 & 10 & 19 \\
\hline
\end{tabular}

Table 3. The Chi square test results for the comparisons: students in Zlin and students in Trencin for the options of answers "yes" and "In the middle or I don't know".

\begin{tabular}{|ccc|}
\hline & Yes & $\begin{array}{c}\text { In the middle or } \\
\text { I don't know }\end{array}$ \\
\hline Students in Zlin (27) & 11 & 11 \\
\hline Students in Trencin (27) & 5 & 13 \\
\hline Pearson uncorrected and $p<$ & 2.037 & 0.154 \\
\hline Yates corrected and $p<$ & 1.216 \\
\hline
\end{tabular}

The intuitively comprehensible statement about these results is, however, that 14 Polish, 5 Slovak, and 11 Czech students gave a "yes" answer to question No. 21. The answer \{ "no" or "in the middle", or "I don't know "\} was selected by 19 Polish, 38 Slovak, and 16 Czech students.

The chi-square test results for the above frequencies for the comparison Nysa-Trenczin are: Pearson uncorrected 9.444; $p<0.002$ and Yates corrected 7.873; $p<0.005$. For the comparison Trenczin-Zlin, the calculated values were Pearson uncorrected 7.97; $p<0.002$ and Yates corrected 6.40; $p<0.011$. For the comparison Nysa-Zlin, the calculated chi-square values were not statistically significant.

These results could be analyzed in more detail by separating the answers "no" and "in the middle" or "I don't know". We present this arrangement of results in Tables 3 and 4.

It appears that even in the Czech Republic, many young people (approx. 60\%) do not consider the liberalization of legislation for the possession of small amounts of drugs as appropriate. The proportion of young Polish students who do not positively assess such legislation is similar. In Slovakia, young people overwhelmingly judge such legislation negatively or have no opinion on this subject.

The average ability to work together, estimated by the arithmetic average score for questions 1-20, obtained by students from
Table 4. The Chi square test results for the comparisons: students in Zlin and students in Trencin for the options of answers "yes" and "no".

\begin{tabular}{|ccc|} 
& Yes & No \\
\hline Students in Zlin (27) & 11 & 5 \\
\hline Students in Trencin (27) & 5 & 25 \\
\hline Pearson uncorrected and $p<$ & 0.00001 & \\
\hline Yates corrected and $p<$ & 12.47 & 0.28 \\
\hline
\end{tabular}

Nysa was 16.33, and was similar among students in Trenčín (15.02) and Zlin (16.90). The averages were similar and the observed differences were not significant.

\section{Discussion}

Interpretation of the results is difficult, mainly because of the small size of the sample groups. Nevertheless, our initial pilot results are surprising and incline us to encourage extensive research on the equivalent attitudes of citizens in different European countries. Many journalists, psychologists, and doctors in the Netherlands, Portugal, and the Czech Republic assessed the individual and social consequences of such regulations as beneficial [15-18].

Hannah Laqueur discussed in details [19] the opinion of the Cato Institute, a major libertarian think-tank in the United States, which issued on 2009 a report on drug law reforms implemented by Portugal in 2001 [18]. He remembers that Portugal's reforms decriminalized the acquisition, possession, and personal use of small quantities of all psychoactive drugs, including heroin and cocaine. Hannah Laqueur emphasized that Glenn Greenwald from the Cato Institute argued that "judged by virtually every metric, the Portuguese decriminalization framework has been a resounding success". Hannah Laqueur cited a similar opinion among many high-volume journals. These conclusions have been widely accepted; 
however, there are some authors who believe there is still a problem. Sznitman and Zlotove discuss the possible impact of legalization, already implemented in many countries, of the use of cannabis for therapeutic purposes (CTP) on public health and safety [20].

In light of these data, it is difficult to explain the results obtained by our survey. Clarification of the existence of such a large proportion of young people in Poland, Slovakia, and even the Czech Republic, who negatively assess such legislation liberalization requires in-depth psychological analysis. Currently, it is only possible to formulate "psychoanalytic" hypotheses, which should be verified.

It seems to us that many people living in Central European countries have rooted prejudices against facilitating the induction of altered states of consciousness, with the exception of the use of alcohol. The same reflexes can be noted in young doctors working in hospitals who are parsimonious with the application of drugs such as morphine in patients suffering from pain caused by cancers. The observations of Krystosek agree with our results. He found that "greater religiosity reduces the likelihood of support for legalization" [21].

The discussed attitude is probably related to the overriding beliefs concerning the rights of any human to liberty and freedom of decision-making. Many people in these countries do not want to gain greater freedom. One must suspect that many citizens of these countries are convinced of the need for strict control of behavior and penalties by "wiser" persons in authority.

It seems to us also that the described attitude has some connection with the low values obtained on the scale of the ability to cooperate. High social capital is manifested by high social

\section{References:}

1. Nutt D, King LA, Saulsbury W, Blakemore C: Development of a rational scale to assess the harm of drugs of potential misuse. Lancet, 2007; 369: 1047-53

2. Nutt DJ, King LA, Phillips LD: Drug harms in the UK: A multicriteria decision analysis. Lancet, 2010; 376: 1558-65

3. van Amsterdam J, Nutt D, Phillips L, van den Brink W: European rating of drug harms. J Psychopharmacol, 2015; 29: 655-60

4. van Amsterdam J, Opperhuizen A, Koeter M, van den Brink W: Ranking the harm of alcohol, tobacco and illicit drugs for the individual and the population. Eur Addict Res, 2010; 16: 202-7

5. Martinotti G, Lupi M, Carlucci L et al: Novel psychoactive substances: Use and knowledge among adolescents and young adults in urban and rural areas. Hum Psychopharmacol, 2015; 30: 295-301

6. Zawilska JB, Andrzejczak D: Next generation of novel psychoactive substances on the horizon - A complex problem to face. Drug Alcohol Depend, 2015; 157: 1-17

7. Brodziak A, Wieczorek L: Mysterious wave of severe poisonings in poland by new psychoactive substances. mysterious wave of severe poisonings in Poland by new psychoactive substances. J Gerontol Geriatr Res, 2016; 5: 269 activity and a vibrant, innovative industry and economy. The scientific achievements of a country especially depend on the level of social capital. The Czech Republic, Hungary, Poland, and Slovakia have rather mediocre results in the field of scientific investigations [22]. It seems that in this situation it is worth looking for psychological and social reasons of the poor ability to cooperate. It seems to us that the first thinking and investigations should concern psychological and social causes of passivity.

\section{Conclusions}

1. A significant proportion of young people in the Czech Republic, Poland, and Slovakia do not approve of the liberalization of legislation on possession of small amounts of marijuana and other drugs.

2. It is necessary to verify the "psychoanalytic" hypotheses explaining the nature of these prejudices.

3. One must suspect that many citizens of these countries do not condone the right to freely make personal decisions based on temporary changes in perception.

4. The lack of social approval for the legal possession of small amounts of marijuana makes it difficult to fight dangerous "new psychoactive substances".

5. Data about the consequences of the liberalized legislation introduced in some countries are scarce, and their significance is ambiguous; therefore, there is a need for in-depth population-based studies to clarify these issues.

\section{Conflict of interests}

The authors declare that they have no competing interests.

8. Brodziak A. The harm caused by marihuana use disorders is interrelated in some European countries to the harm caused by new psychoactive substances. Nursing and Palliative Care (NPC) - OAT - Open access text. 2016; 1(1) doi: $10.15761 / .1000106$

9. Pedersen W, Fjaer EG, Gray P, von Soest T: Perceptions of harms associated with tobacco, alcohol, and cannabis among students from the UK and Norway. Contemporary Drug Problems, 2016; 43(1): 47-62

10. Sobesky M. Gorgens K. Cannabis and adolescents: Exploring the substance misuse treatment provider experience in a climate of legalization. Int I Drug Policy, 2016; 33: 66-74

11. McPherson KE, Kerr S, McGee E et al: The association between social capital and mental health and behavioural problems in children and adoles cents: an integrative systematic review. BMC Psychol, 2014; 2(1): 7

12. McPherson KE, Kerr S, Morgan A et al: The association between family and community social capital and health risk behaviours in young people: An integrative review. BMC Public Health, 2013; 13: 971

13. Ballard PJ, Syme SL: Engaging youth in communities: a framework for promoting adolescent and community health. J Epidemiol Community Health, 2016; 70(2): 202-6 
14. Brodziak A, Grabczak P, Różyk-Myrta A, Kołat E: [An attempt to asses the predisposition and skills of interactions and collaboration in selected groups of nursing students in Poland and Slovakia] - in Polish. The chapter in the monoghraph: [Demographic crisis - reasons and ways of counteracting in context of own international investigations]. Editorial Office of the University of Applied Sciences in Nysa, Poland, 2016

15. Csete J, Kamarulzaman A, Kazatchkine $M$ et al: Public health and international drug policy. Lancet, 2016; 387: 1427-28

16. Belackova V, Maalsté N, Zabransky T, Grund JP: "Should I Buy or Should I Grow?" How drug policy institutions and drug market transaction costs shape the decision to self-supply with cannabis in the Netherlands and the Czech Republic. Int J Drug Policy, 2015; 26: 296-310

17. Gonçalves R, Lourenço A, Silva SN: A social cost perspective in the wake of the Portuguese strategy for the fight against drugs. Int J Drug Policy, 2015 26: $199-209$
18. Greenwald G: Drug decriminalization in Portugal: Lessons for creating fair and successful drug policies. Cato Institute - White papers, 2009, NW Washington, DC 20001-5403, 1000 Massachusetts Ave

19. Hannah L: Uses and abuses of drug decriminalization in Portugal. Law and Social Inquiry, 2015; 40: 746

20. Sznitman S, Zolotov Y: Cannabis for Therapeutic Purposes and public health and safety: A systematic and critical review. Int J Drug Policy, 2015; 6: 20-29

21. Krystosek DJ: Thou shalt not: Religiosity and attitudes toward marijuana legalization. International Journal of Law, Crime and Justice, 2016, 10.1016/j. ijlcj.2016.08.001

22. Academic ranking of world universities. The report announced on 8.08.2016. http://www.shanghairanking.com/index.html 